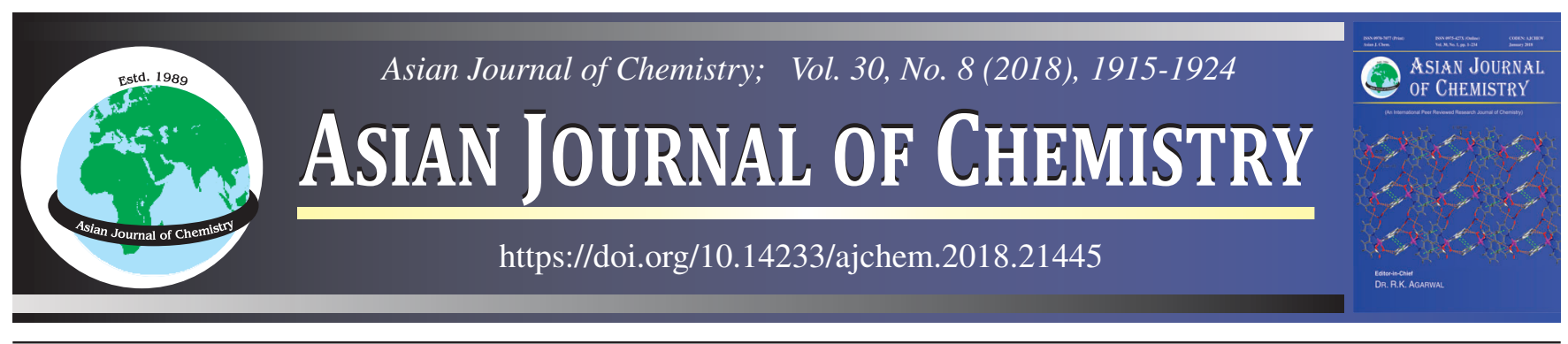

\title{
LC-MS Compatible Stability Indicating RP-UPLC Method for the Estimation of Ester Prodrug of Mycophenolic Acid in Injection Formulation
}

\section{G. Venkata Narasimha RaO ${ }^{1, *}$, Muralee Krishna ${ }^{1}$, Ravi Kumar Bellam ${ }^{2}$ and R. Venkata Nadh ${ }^{3}$}

${ }^{1}$ Formulations Research and Development Centre, Glenmark Pharmaceuticals Ltd., Taloja, Mumbai-410 208, India

${ }^{2}$ School of Biotechnology, VIGNAN University, Vadlamudi-522 213, India

${ }^{3}$ Department of Chemistry, GITAM University, Bengaluru-562 163, India

*Corresponding author: E-mail: venkata.nr@gmail.com

Received: 14 May 2018;

Accepted: 12 June 2018;

Published online: 30 June 2018;

AJC-18996

This study explores the ultra performance liquid chromatography for the quantification of mycophenolate mofetil (an immunosuppressant agent) in an injection formulation. Mycophenolate mofetil was separated from its seven specified impurities on HSS (high strength silica) C18 column $(100 \times 2.1 \mathrm{~mm}, 1.8 \mu \mathrm{m})$. The optimized mobile phase is compatible to mass spectrometry and hence the method can be equally run on LC-MS system for mass determinations. Efficient UV detection at $250 \mathrm{~nm}$ enabled determination of mycophenolate mofetil with no interference from placebo solution, diluent and other specified and unspecified impurities. The retention time of mycophenolate mofetil in the method was $1.79 \mathrm{~min}$ and all other impurities were eluted within in 8 min. The method optimization studies show that the selectivity of mycophenolate mofetil and its impurities was dependent on the type of organic solvent and its elution strength. The method was validated for specificity, linearity, precision, accuracy and robustness in range of 50 to $150 \%$ of target analyte concentration (i.e. 62.50-195.31 $\mu \mathrm{g} \mathrm{mL}^{-1}$ ). The linearity of peak area responses versus concentrations was demonstrated by linear least square regression analysis. An excellent linear relation exists between the concentration and detector response $\left(\mathrm{R}^{2}>0.9999\right)$. Precision of the test method was proved with a relative standard deviation less than $1.0 \%$.

| Keywords: UPLC, Mycophenolate mofetil, Stability, Indicating assay, Validation.

\section{INTRODUCTION}

Mycophenolate mofetil is an immunosuppressant drug [1]. Immunosuppressant drugs belong to a class of drugs that reduce or suppress the immune strength of the body. These are used during organ transplantation or for an autoimmune disorder [2]. Mycophenolate mofetilis is an ester prodrug of mycophenolic acid (MPA), which is the main active moiety. Other drugs, which are employed in immunosuppressive therapy are cyclosporine A, azathioprine, prednisone FK-506 (Tacrolimus), Rapamycin (Sirolimus), etc. Though cyclosporine A was a choice of drug among the immunosuppressants in 1970's, it is associated with certain side effects like hypertension, hypercholes-terolemia, nephrotoxicity, diabetogenic effects and neurotoxicity. Azathioprine and prednisone were found ineffective in providing adequate immunosuppression for patients having complex kidney problems and who further require liver or heart transplantation. Among these immunosuppressants mycophenolate mofetil has emerged as a novel potent drug with enhanced bioavailability and reduced toxicities that are associated with the above mentioned drugs $[3,4]$.
Mycophenolate mofetil is a white to off white crystalline substance with an empirical formula $\mathrm{C}_{23} \mathrm{H}_{31} \mathrm{NO}_{7}$. Its molecular weight is 433.49. Its chemical name is $(E)$-2-morpholinoethyl (E)-6-(4-hydroxy-6-methoxy-7-methyl-3-oxo-5-phthalanyl)4-methyl-4-hexenoate. It is slightly soluble in water. The reported solubility in water is $43 \mathrm{mg} \mathrm{mL}^{-1}[5,6]$. It has two $\mathrm{pKa}$ values, 5.6 and 8.5 for morpholine group and phenolic group respectively. The existing dosage forms of mycophenolate mofetil are tablets, capsules, oral suspension and injection [7]. The current study utilizes its injection formulation for new analytical method.

Mycophenolate mofetil is a pro-drug and a morpholino ethyl ester of mycophenolic acid (MPA). In 1913, MPA was first isolated from the culture of Penicilliumstoloniferum [8]. It was then reported as a metabolic product from Penicillium brevicompactum, Penicillium brevicompactum and Penicillium stoloniferum, which also belong to same series of Penicillium [9].

The chemical structure of MPA was determined in 1952, while its crystal structure was reported in 1972 [10,11].

Mycophenolate is official in United States Pharmacopoeia (USP) and European Pharmacopeia (Ph. Eur) and Indian Pharmacopoeia [12-17]. The potential impurities of myco- 
phenolate mofetil are listed in Table-1 [16]. USP compendia contains monographs of different dosage forms (mycophenolate mofetil for injection, capsules, tablets, delayed release tablets and oral suspension).

$\mathrm{Ph}$. Eur monographs contain titrimetric method and HPLC method for assay of mycophenolate mofetil and related substances, respectively. The mobile phase consists of a mixture of acetonitrile and water $(35: 65 \mathrm{v} / \mathrm{v})$ containing $2 \mathrm{~mL}$ of triethylamine ( $\mathrm{pH} 5.3$ with dil. $\mathrm{H}_{3} \mathrm{PO}_{4}$ ). The separation of sample components was carried out on C8 (octylsilyl) column with dimensions $250 \mathrm{~mm} \times 4.6 \mathrm{~mm}, 5 \mu \mathrm{m}$. The flow rate was 1.5 $\mathrm{mL} \min ^{-1}$ and detection wavelength was $250 \mathrm{~nm}$. USP monograph for mycophenolate mofetil prescribes a common method for assay of it and it's organic impurities. The method follows an isocratic separation with a mixture of acetonitrile and triethylamine buffer (pH 5.3) in the ratio 7:13 v/v. The column and other chromatographic conditions are like the above stated method in Ph. Eur monograph. A separate method is available for assay of it and it's organic impurities present in USP for injection formulation. The method comprises of a triethyl-

TABLE-1

NAMES, CHEMICAL STRUCTURES AND NATURE OF MYCOPHENOLATE IMPURITIES [Ref. 16]

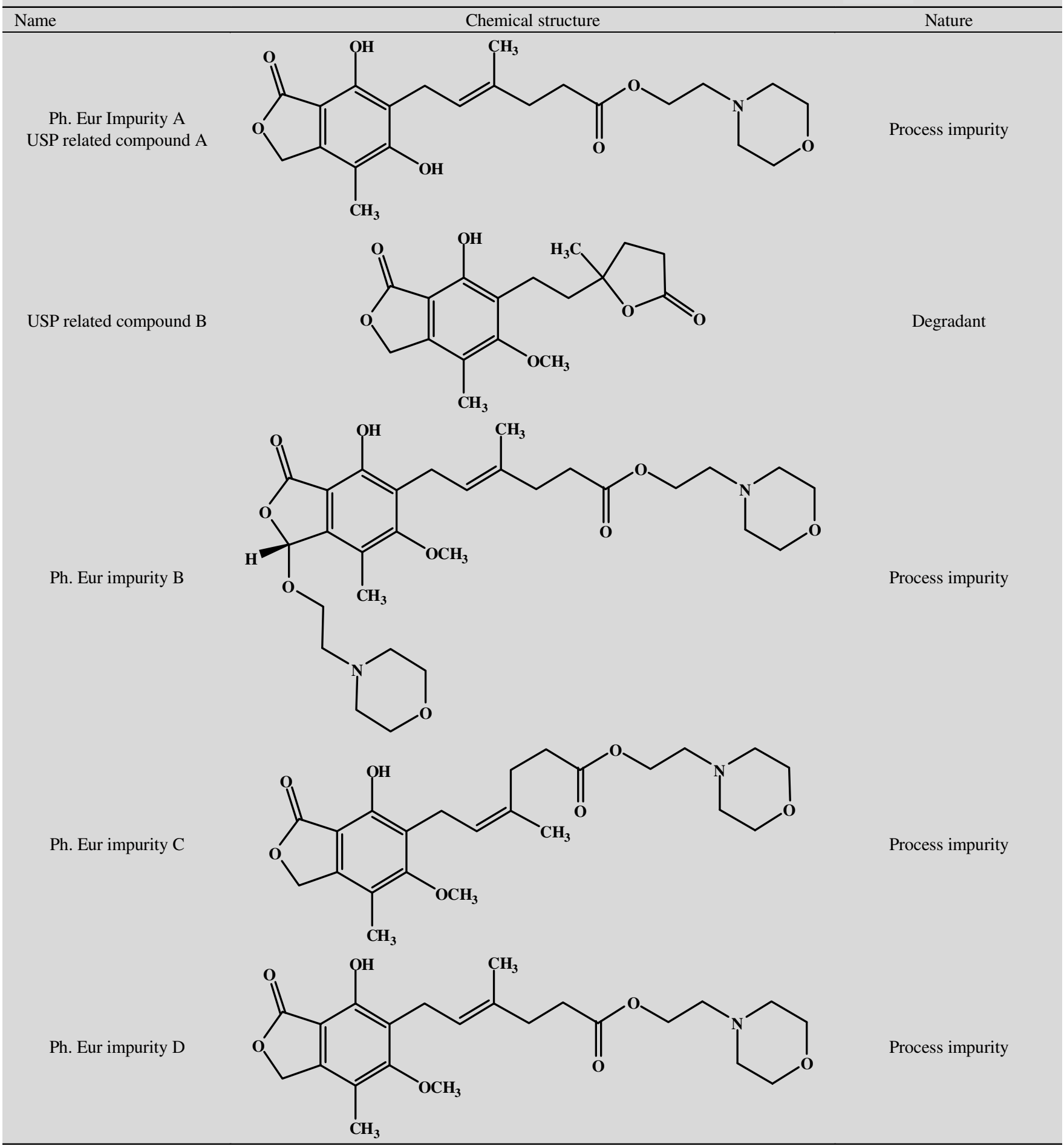


Ph. Eur impurity E

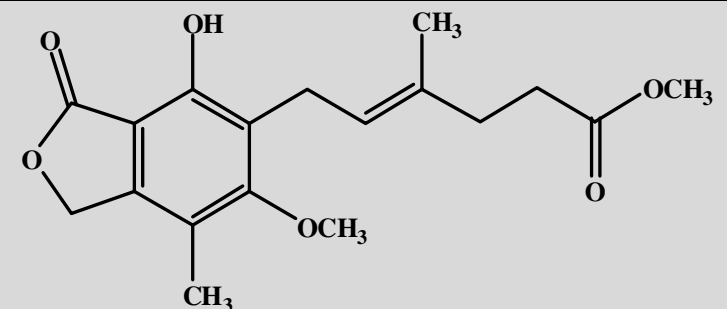

Degradant

Ph. Eur impurity F

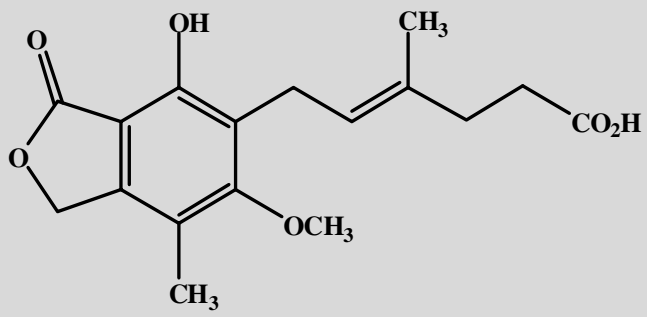

Process impurity

amine buffer ( $\mathrm{pH} 7.2$ ) mixed with acetonitrile in the ratio 7:3 $\mathrm{v} / \mathrm{v}$, as the mobile phase. The separation was carried out on phenyl (L11) column $(250 \mathrm{~mm} \times 4.6 \mathrm{~mm}, 5 \mu \mathrm{m})$. A similar method consisting of triethylamine buffer and L11 column is available in USP for the determination of mycophenolate mofetil in oral suspension. Similarly, methods are available in USP for the determination of mycophenolate mofetil in tablets and capsule formulations. These methods also use the same mobile phase containing triethylamine and acetonitrile, C8 column as described in, for other formulations in USP. Indian Pharmacopoeia publishes two methods for mycophenolate mofetil API and capsules dosage form IP. First method is similar to that of $\mathrm{Ph}$. Eur monograph. $\mathrm{C}_{18}$ column of dimensions $250 \mathrm{~mm} \times 4.6 \mathrm{~mm}, 5 \mu \mathrm{m}$ was used for the analysis of related substances. The assay of mycophenolate mofetil in IP monograph is estimated using a titrimetric method.

Thorough literature survey revealed few reported methods on the determination of mycophenolate mofetil by HPLC and UPLC methods. One HPLC method was reported on the determination of mycophenolate mofetil in human plasma [18]. The method uses a mobile phase containing a buffer $(\mathrm{pH} 3.6)$ and acetonitrile mixed in the ratio 59:41 v/v. The buffer contains citratephosphate $(0.05 \mathrm{M})$ and heptanesulphonic acid $(0.02$ $\mathrm{M})$. The mobile phase was pumped at $0.4 \mathrm{~mL} \mathrm{~min}^{-1}$ and detection was carried at $254 \mathrm{~nm}$. The separation was performed on a C18 column $(150 \mathrm{~mm} \times 4.6 \mathrm{~mm}, 5 \mu \mathrm{m})$. Mycophenolate mofetil elutes at about $15 \mathrm{~min}$ and the total run time of the method was $25 \mathrm{~min}$. An isocratic HPLC method is available for the determination of mycophenolate mofetil in pure and tablets dosage form [19]. The method comprises of phosphate buffer (0.03 M containing $1 \mathrm{~mL}$ of triethylamine, $\mathrm{pH} 2.9$ ) mixed with acetonitrile in the ratio $60: 40 \mathrm{v} / \mathrm{v}$ as the mobile phase. The separation was carried out on a $\mathrm{C}_{18}$ column with dimensions $250 \mathrm{~mm} \times 4.6 \mathrm{~mm}, 5 \mu \mathrm{m}$. The method lacks discussion on specificity of listed impurities and forced degradation studies.

One reversed phase UPLC method was reported on quantitation of mycophenolate mofetil in tablets dosage form [20]. The separation was carried on a symmetry C18 column (100 $\mathrm{mm} \times 4.6 \mathrm{~mm}, 3.5 \mu \mathrm{m}$ ) using a mobile phase composed of phosphate buffer and acetonitrile mixed in the ratio 35:65 v/v. Mycophenolate mofetil in tablets was detected at $228 \mathrm{~nm}$. The method lacks discussion on forced degradation studies and no specified impurities were discussed in specificity. Another UPLC method was reported on forced degradation study and quantification of mycophenolate in tablets [21]. This method was developed on BEH column having dimensions $2.1 \mathrm{~mm} \times$ $100 \mathrm{~mm}, 1.7 \mu \mathrm{m}$. The mobile phase used in the method was a combination of phosphate buffer and acetonitrile (35:65 v/v) pumped at a flow rate of $0.4 \mathrm{~mL} \mathrm{~min}^{-1}$. Few HPLC methods were found on the analysis of mycophenolate acid and mycophenolate acid glucuronide in biosamples [22-31]. These methods used similar mobile phases as reported above and carried out separations on conventional reversed phase columns coupled with mass spectrophotometer. The literature reveals that no single short method is reported on the estimation of mycophenolate mofetil in injection formulation in presence of its potential impurities. Hence, an attempt is made to develop a shorter method which is also mass compatible.

\section{EXPERIMENTAL}

The HPLC grade acetonitrile and A.R. grade ammonium acetate used in the preparation of mobile phase were obtained from Merck, India. The reference standards and impurity standards were procured from USP and Ph.Eur.

An integrated Acquity UPLC system is from Waters Corporation, Milford, USA and equipped with a Waters photodiode array detector (PDA). Data collection and analysis were performed using the Empower software 2pro (Waters Corporation). Balances used for weighing the reference standards and samples were from Mettler Toledo. The columns HSS T3 was procured from Waters India Pvt. Ltd. Class A glasswares used in conducting the experiments and validations was from Duran and Borosil, India.

\section{Standard and sample preparations}

Diluent preparation: A mixture of acetonitrile and water $(90: 10 \mathrm{v} / \mathrm{v})$ was used for the preparation of diluent, standards, system suitability solutions and sample solution. This selection was based on the solubility studies conducted on the active drug substance.

Preparation of mycophenolate working standard solution: Accurately weighed and transferred $39 \mathrm{mg}$ of mycophenolate working standard into $50 \mathrm{~mL}$ volumetric flask. Added $25 \mathrm{~mL}$ of the diluent and sonicated for $2 \mathrm{~min}$ to dissolve the 
contents. Made up to the mark with the diluent. Further transfer $4 \mathrm{~mL}$ of the above solution into $25 \mathrm{~mL}$ volumetric flask and made up to the mark with the diluent to attain a concentration of $125 \mu \mathrm{gL}^{-1}$.

Preparation of mycophenolate impurity mixed stock solution: Accurately weighed and transferred $2.5 \mathrm{mg}$ of each impurity of mycophenolate into $100 \mathrm{~mL}$ volumetric flask. Added $25 \mathrm{~mL}$ of the diluent and sonicated for $2 \mathrm{~min}$ to dissolve the contents. Made up to the mark with the diluent.

Preparation of sample solution (mycophenolate for injection $6 \mathrm{mg} / \mathrm{mL}$ ): Taken five vials of mycophenolate powder for injection, reconstituted each vial as recommended in the PIL (Product Information Leaflet). Pooled the contents of all three vials. Pipetted $5 \mathrm{~mL}$ of the sample into $25 \mathrm{~mL}$ volumetric flask. Added $15 \mathrm{~mL}$ of the diluent and sonicated for $2 \mathrm{~min}$ to mix the contents. Made up to the mark with the diluent. Further diluted $2.6 \mathrm{~mL}$ of the above solution to $25 \mathrm{~mL}$ with diluent and mixed well to get the final concentration of $125 \mu \mathrm{g} \mathrm{mL}^{-1}$.

Preparation of sample solution spiked with impurity mixture: Pipetted $5 \mathrm{~mL}$ of reconstituted sample into $25 \mathrm{~mL}$ volumetric flask. Added $15 \mathrm{~mL}$ of diluent and sonicated for 2 min to mix the contents. Made up to the mark with the diluent. Further pipetted $2.6 \mathrm{~mL}$ of the above solution and $2.5 \mathrm{~mL}$ of the impurity mixed stock solution into $25 \mathrm{~mL}$ volumetric flask and diluted up to the mark with the diluent. Mixed well to get a final concentration of $2 \%$ of impurities.

Preparation of placebo solution: Transferred $5 \mathrm{~mL}$ of the placebo solution to $25 \mathrm{~mL}$ volumetric flask. Added $15 \mathrm{~mL}$ of the diluent and sonicated for 2 min to mix the contents. Made up to the mark with the diluent. Further diluted $2.6 \mathrm{~mL}$ of the above solution to $25 \mathrm{~mL}$ with diluent and mixed well.

\section{RESULTS AND DISCUSSION}

Method development and optimization: The diluent used for preparing the standard, system suitability, impurity standards sample and placebo solution was based on the solubility studies conducted for mycophenolate as per USP general notices (5.30. Description and solubility) (USP 40-NF35) [32]. Based on the obtained data and sample matrix, a mixture of acetonitrile and water $(90: 10 \mathrm{v} / \mathrm{v})$ was selected as the diluent

The detection wavelength was determined by injecting a detectable concentration of USP mycophenolate mofetil reference standard into the chromatographic system having photodiode array (PDA) detector. The obtained spectrum exhibits maxima at 304.3, 250.1 and at $215.3 \mathrm{~nm}$ (Fig. 1). However, owing to the possible interferences from organic solvents and inactive excipients the wavelength $215 \mathrm{~nm}$ was not considered. $304.3 \mathrm{~nm}$ has lesser absorbance than $250.1 \mathrm{~nm}$. Hence based on the UV spectra, literature and USP, Ph. Eur monographs and required sensitivity, $250 \mathrm{~nm}$ was selected as the $\lambda_{\max }$ for detection of mycophenolate mofetil.

Method development (selection of chromatographic conditions): The method was developed using the principles of reversed phase chromatography (RPC). The basis for choosing the RP chromatography is the nature and type of the selected compound. Mycophenolate mofetil is a low molecular weight, ester pro-drug of mycophenolic acid (MPA) [8] and hence is a neutral molecule. Reversed phase chromatography is the first

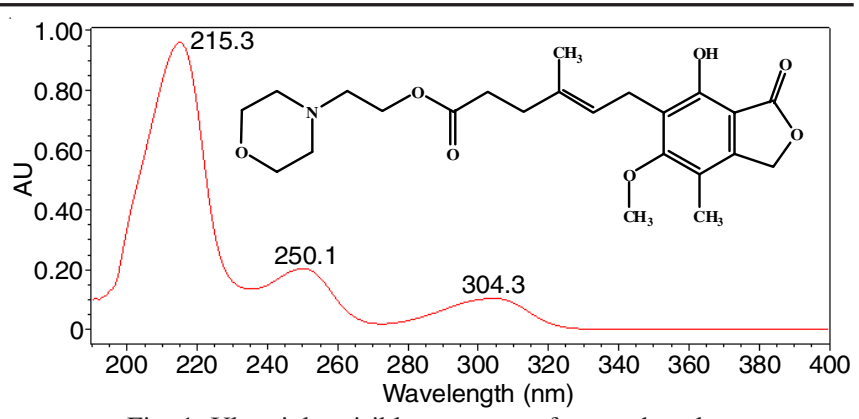

Fig. 1. Ultraviolet-visible spectrum of mycophenolate

choice for neutral molecules having molecular weight less than $2000 \mathrm{Da}[33,34]$.

Trial-1: For initial development trials, the most common $\mathrm{RP}$ column i.e., $\mathrm{C} 18$ column with dimensions $150 \mathrm{~mm} \times 4.6$ $\mathrm{mm}$ and particle size $5 \mu \mathrm{m}$ was chosen. C18 (octadecyl silyl) is the most common RP stationary phase in which long chain alkyl groups are bonded to silica. These are rugged and operate in a wide $\mathrm{pH}$ range ( $\mathrm{pH} 2-8)$. Since mycophenolate mofetil is hydrophobic in nature, pure water cannot be used as an eluent. This is because water being highly polar, repels the hydrophobic molecules and hence the retention times are delayed [35]. The first development strategy contains a mixture of aqueous and non-aqueous mobile phase i.e., Buffer: acetonitrile $(80: 20 \mathrm{v} / \mathrm{v})$. Ammonium acetate was chosen as the buffer (0.01 M) at pH 5.8 (based on mycophenolate mofetil pKa 6.19) [5]. Acetonitrile was chosen based on the molecule solubility for diluent compatibility. The flow rate of the pump was to set 1.0 $\mathrm{mL} \mathrm{min}^{-1}$. The initial column oven temperature was set at 30 ${ }^{\circ} \mathrm{C}$. With these set of chromatographic conditions, a mixture of mycophenolate mofetil reference standard spiked with USP impurities and $\mathrm{Ph}$. Eur. Peak identification mixture $(20 \mu \mathrm{L})$ was injected into the chromatograph. The chromatogram obtained from trial 1 is shown in Fig. 2. Three impurities were separated from the main compound and remaining were found merged with mycophenolate mofetil peak.

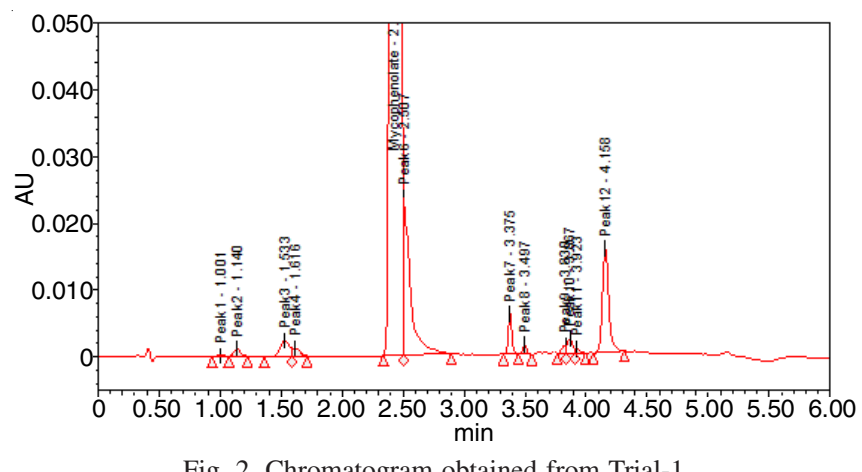

Fig. 2. Chromatogram obtained from Trial-1

Trial-2: Since the structures of few impurities are similar to one another, isocratic mode of separation was ineffective in separating all impurities from the principal peak (mycophenolate mofetil). Hence in the next trial, a gradient programme-1 ( $\mathrm{T}$ (min)/\%B: $0 / 20,0.6 / 25,0.8 / 30,0.9 / 25,1.2 / 20,5 / 20$ ) was introduced to improve separation from the principal peak and the mobile $\mathrm{pH}$ was modified by 0.5 units ( $\mathrm{pH} 4.5$ ). The remaining chromatographic conditions were retained as such. The obtained chromatogram with trial-2 is shown in Fig. 3. 


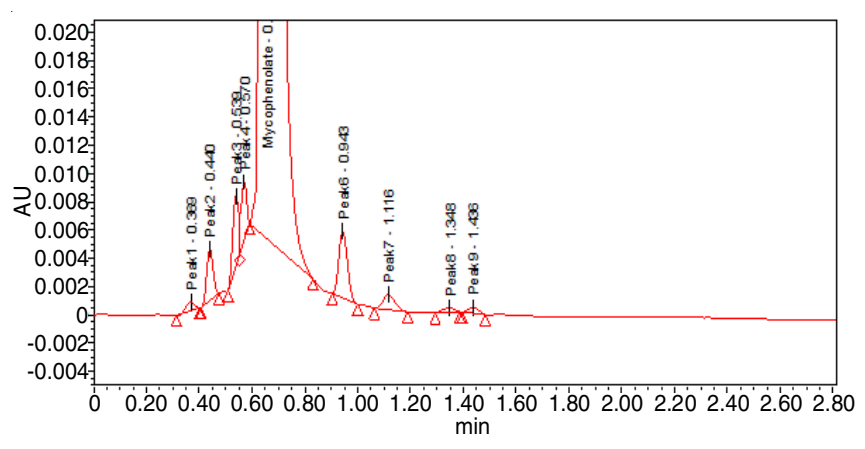

Fig. 3. Development chromatogram obtained from Trial-2

The inference was that three more impurities were resolved from mycophenolate mofetil peak with resolution $<1.0$. From the experiment, it can be observed that an increase in of $10 \%$ acetonitrile from $0 \mathrm{~min}$ to $0.8 \mathrm{~min}$, has resulted improved resolution between the analytes and their selectivity $(\alpha)$. This indicates that the analyte peaks are sensitive to organic modifier in the mobile phase.

Trial-3: An attempt was made by changing the organic modifier from acetonitrile to methanol. The remaining chromatographic conditions including the gradient programme-1 was retained as such. The obtained chromatogram from trial-3 is shown in Fig. 4. Again, few peaks were observed merging with the principal peak, resolution was reduced between USP related compound B and principal peak. The selectivity differs with respect to the acidity, basicity and polarity index of methanol $(\mathrm{PI}=5.1)$ and acetonitrile $(\mathrm{PI}=5.8)$.

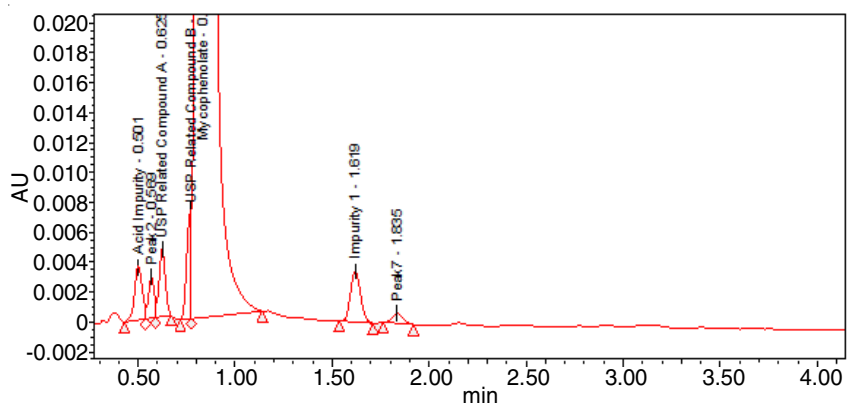

Fig. 4. Development chromatogram obtained from Trial-3

Trial-4 and method optimization studies: In trial-4 acetonitrile was retained in place of methanol and the column C18 was replaced with another brand of C18 (HSS C18) with higher carbon $(15 \%)$ content [36,37]. Literature shows that a higher carbon loading and smaller particle size effect the selectivity and which in turn effects the resolution between the sample components. Hence, the selectivity increases with an increase in carbon content [38]. The new column dimensions are $100 \mathrm{~mm} \times 2.1 \mathrm{~mm}, 1.8 \mu \mathrm{m}$. Here the pore size is reduced from 5 to $1.8 \mu \mathrm{m}$. Different flow rates were studied to understand the chromatographic pattern $(0.3,0.5,0.8$ and $1.0 \mathrm{~mL}$ $\left.\mathrm{min}^{-1}\right)$. The effect of temperature on the separation was studied at $35,40,45$ and $50{ }^{\circ} \mathrm{C}$. Separation was achieved for all the peaks and also between the USP related compound B and mycophenolate was $>2.0$. Optimal resolution was achieved at column oven temperature $45^{\circ} \mathrm{C}$ and flow rate $0.3 \mathrm{~mL} \mathrm{~min}{ }^{-1}$. Impurity 2 which was late eluting in previous trials has eluted at higher organic composition (a gradient programme-3, ( $\mathrm{T}$ (min)/\%B: 0/60, 3/60, 4/80, 6/80, 6.5/60, 9/60). The optimized chromatogram is shown in Fig. 5, while an un-zoomed chromatogram is shown in Fig. 6. The optimized chromatographic conditions are summarized as: Flow rate: $0.3 \mathrm{~mL} \mathrm{~min}^{-1}$, wavelength: $250 \mathrm{~nm}$, injection volume: $10 \mathrm{~L}$; column oven temperature: $45^{\circ} \mathrm{C}$; mobile phase $\mathrm{A}$ : $0.02 \mathrm{M}$ ammonium acetate $(\mathrm{pH}$ 4.5), mobile phase B: acetonitrile.

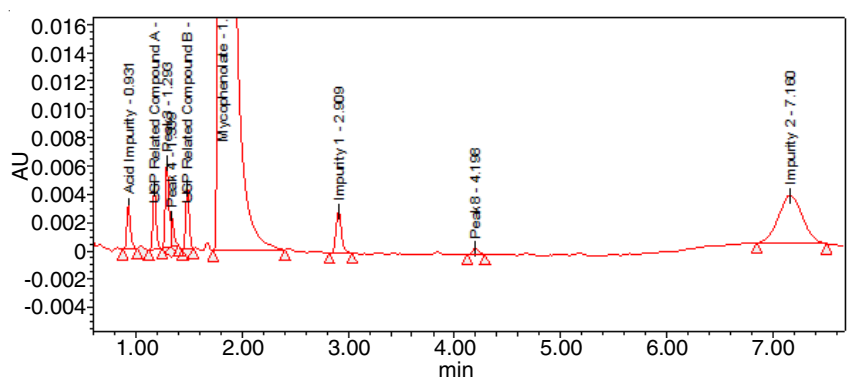

Fig. 5. Development chromatogram obtained from Trial-4

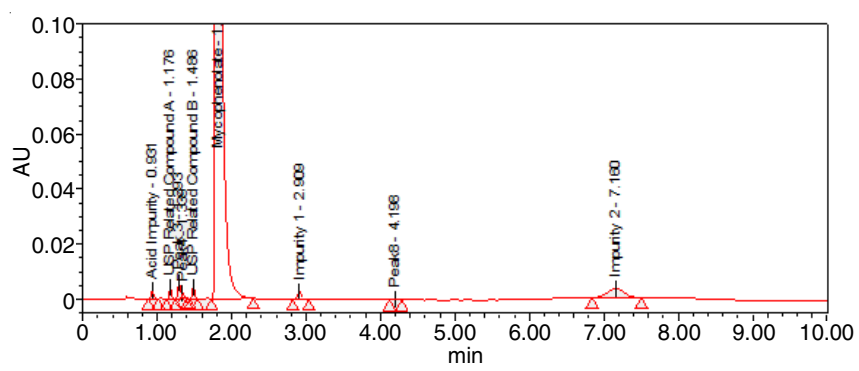

Fig. 6. Development chromatogram obtained from optimized chromatographic conditions

Method validation: The developed and optimized UPLC method was taken up for validation. The method validation was carried out in accordance with the validation guidelines (Q2R) recommended by ICH. The developed UPLC method was validated with respect to system suitability, specificity, accuracy, precision, linearity, limit of detection, limit of quantitation and robustness. Each validation parameter is explained in detailed in below sections.

System suitability and system precision: The system suitability and system precision for the intended analysis were evaluated from five and six replicate injections respectively of standard solution. The typical system suitability chromatogram is shown in Fig. 7. The system suitability parameters like USP tailing factor, USP plate counts and \% RSD for mycophenolate mofetil peak were determined and evaluated (Table-2).

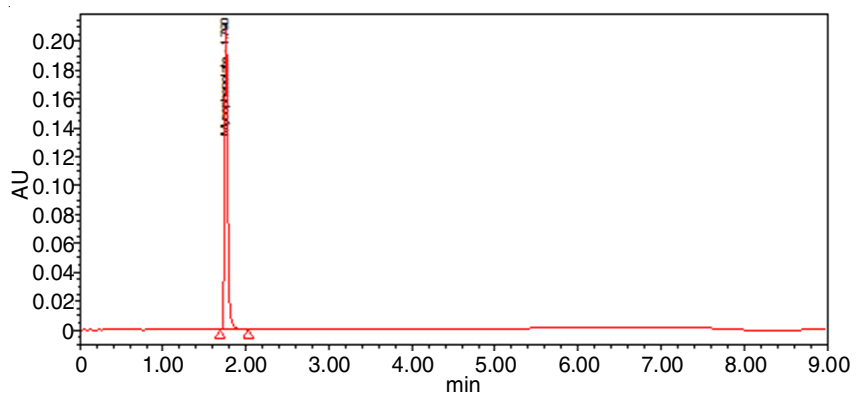

Fig. 7. Typical chromatogram of system suitability 


\begin{tabular}{cccccc}
\hline \multicolumn{5}{c}{ TABLE-2 } \\
RESULTS OF SYSTEM SUITABILITY AND SYSTEM PRECISION
\end{tabular}

\section{Specificity}

Diluent interference: The diluent was injected as such into the chromatograph to assess its interference (if any) at the retention time of mycophenolate mofetil. Mycophenolate mofetil elutes at $1.790 \mathrm{~min}$ and there is no interference at the retention time of $1.790 \mathrm{~min}$ due to the diluent (Fig. 8).

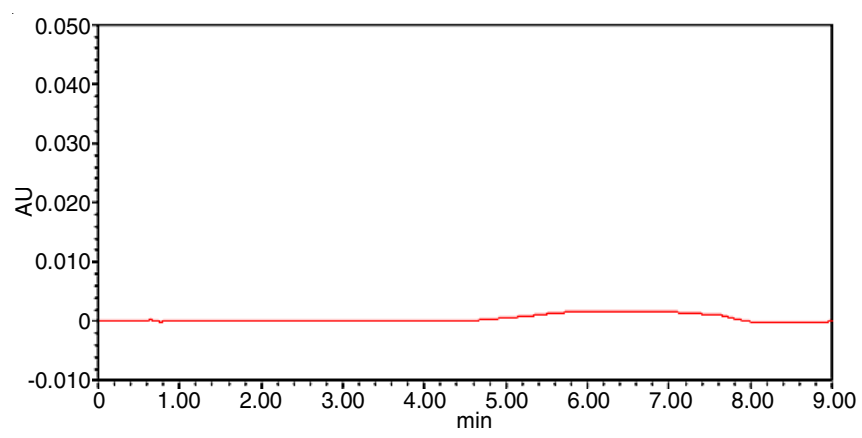

Fig. 8. Typical chromatogram of diluent

Placebo interference: Placebo solution was prepared as per the optimized methodology and injected into the chromatographic system. Mycophenolate mofetil elutes at $1.790 \mathrm{~min}$ and there is no interference at the retention time of $1.790 \mathrm{~min}$ due to the placebo (Fig. 9).

Interference due to specified impurities of mycophenolate: To assess the interference due the specified impurities of

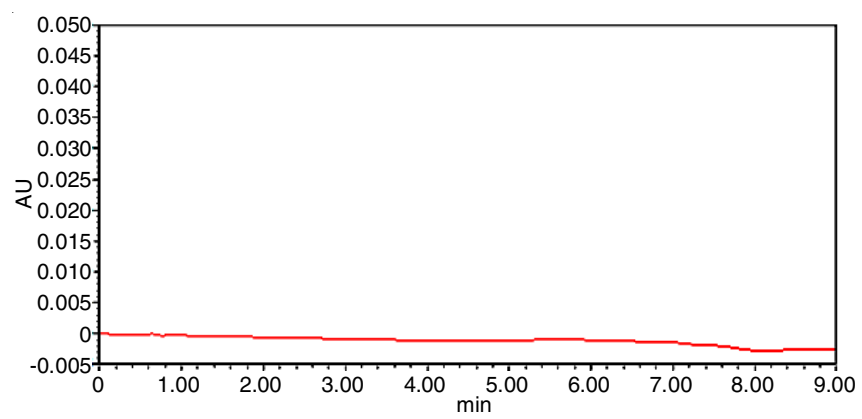

Fig. 9. Typical chromatogram of placebo mycophenolate, a sample solution was spiked with small portion ( $2 \%$ ) of listed impurities (Table-1) by injecting into the chromatographic system. The mycophenolate mofetil peak was evaluated for the homogeneity by measuring the purity angle and purity threshold using the empower software (Figs. 10-13). Assay of mycophenolate mofetil in presence of specified impurity mixture was calculated and compared with that of unspiked sample (Table-3). Assay of the sample spiked with impurities was found $99 \%$ and that of pure sample was $98.8 \%$. The absolute difference $(0.2)$ is very small and indicates that the assay of mycophenolate was unaffected in presence of its impurities. The purity data indicate that the purity angle is less than the purity threshold for all three samples, which concludes that mycophenolate mofetil peak is homogenous and the new method is analyte specific.

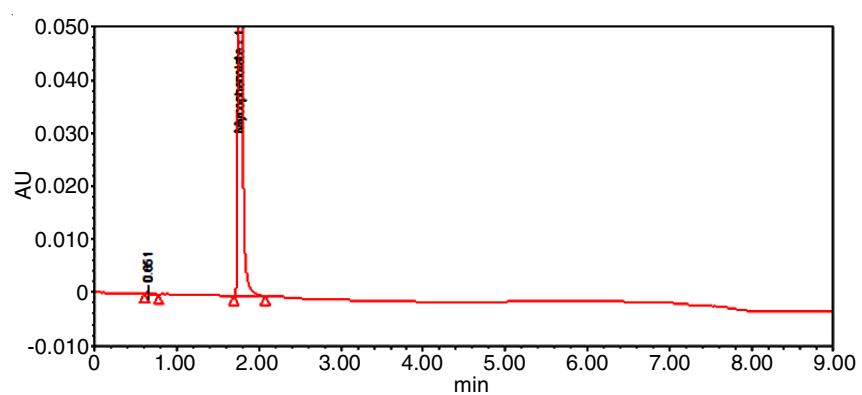

Fig. 10. Typical chromatogram of unspiked sample

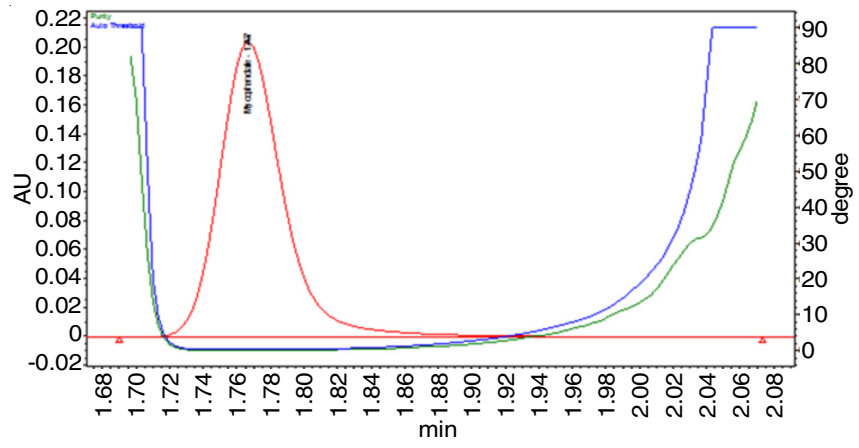

Fig. 11. Purity plot for mycophenolate peak (from unspiked sample)

\begin{tabular}{|c|c|c|c|c|}
\hline \multicolumn{5}{|c|}{$\begin{array}{l}\text { TABLE-3 } \\
\text { COMPARISON OF ASSAY RESULTS AND PEAK PURITY RESULTS OF SAMPLE } \\
\text { SPIKED WITH IMPURITY AND UNSPIKED SAMPLE }\end{array}$} \\
\hline Sample Details & Assay (\%) & Purity angle & Purity threshold & Purity flag* \\
\hline Unspiked sample-1 & 99.4 & 0.127 & 0.345 & No \\
\hline Unspiked sample-2 & 97.9 & 0.332 & 0.484 & No \\
\hline Unspiked sample-3 & 99.2 & 0.135 & 0.242 & No \\
\hline$\%$ Average & 98.8 & NA & NA & No \\
\hline Spiked sample-1 & 99.1 & 0.243 & 0.274 & No \\
\hline Spiked sample-2 & 99.0 & 0.236 & 0.347 & No \\
\hline Spiked sample-3 & 98.9 & 0.136 & 0.346 & No \\
\hline \%Average assay & 99.0 & NA & NA & NA \\
\hline
\end{tabular}




\begin{tabular}{|c|c|c|c|c|c|}
\hline \multicolumn{6}{|c|}{$\begin{array}{c}\text { TABLE-4 } \\
\text { RESULTS OF STRESS STUDY AND PEAK PURITY DATA }\end{array}$} \\
\hline Parameter & Stress Conditions & $\begin{array}{c}\text { \%Assay of } \\
\text { degraded sample } \\
\text { A } \\
\end{array}$ & $\begin{array}{c}\text { Degradation } \\
\text { w.r.t. control } \\
\mathrm{B}^{*}\end{array}$ & $\begin{array}{l}\text { Purity } \\
\text { angle }\end{array}$ & $\begin{array}{l}\text { Purity } \\
\text { threshold }\end{array}$ \\
\hline Control sample & No exposure & 99.1 & NA & 0.143 & 0.302 \\
\hline Acid hydrolysis & $1 \mathrm{~mL}$ of $1 \mathrm{~N} \mathrm{HCl}$ for $3 \mathrm{~h}$ at room temperature & 95.4 & 3.7 & 0.046 & 0.325 \\
\hline Base hydrolysis & $1 \mathrm{~mL}$ of $0.5 \mathrm{~N} \mathrm{NaOH}$ for $3 \mathrm{~h}$ at room temperature & 31.6 & 68.1 & 0.135 & 0.369 \\
\hline Oxidation & $1 \mathrm{~mL}$ of $30 \% \mathrm{H}_{2} \mathrm{O}_{2}$ for $3 \mathrm{~h}$ at room temperature & 89.2 & 10.0 & 0.048 & 0.301 \\
\hline Thermal degradation & $60^{\circ} \mathrm{C}$ for $5 \mathrm{~h}$ & 97.1 & 2.0 & 0.047 & 0.304 \\
\hline Photolytic degradation (UV) & $200 \mathrm{Watt} h / \mathrm{m}^{2}$ & 98.7 & 0.4 & 0.127 & 0.311 \\
\hline Photolytic degradation (light) & 1.2 Million lux hours & 99.1 & 0.0 & 0.114 & 0.320 \\
\hline
\end{tabular}

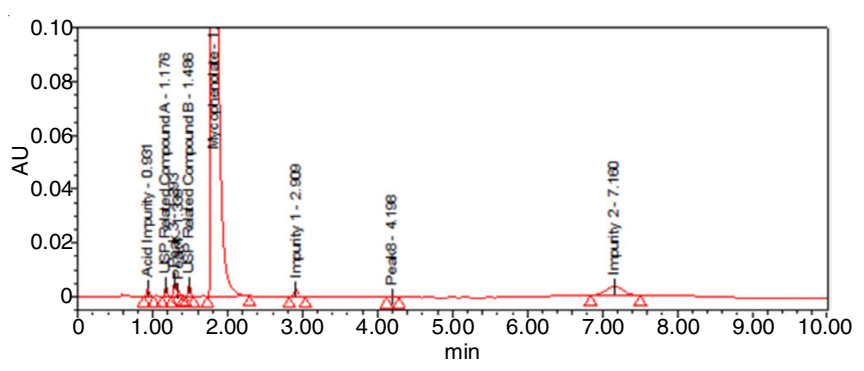

Fig. 12. Typical chromatogram of sample spiked with impurities

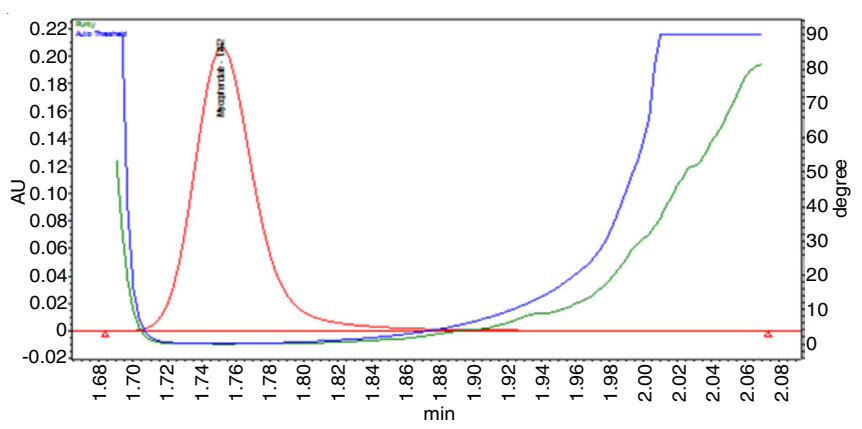

Fig. 13. Purity plot for mycophenolate (from impurity spiked sample)

Interference from degradation products: To assess the interference due to the degradation products, mycophenolate mofetil injection sample and placebo solutions were exposed to various stress conditions. The stressed and neutralized samples were then diluted with the diluent to obtain a concentration of about $125 \mu \mathrm{g} \mathrm{mL}^{-1}$. The obtained solutions were chromatographed as per the optimized methodology. All chromatograms were processed by using the Empower 2 pro software. The homogeneity of mycophenolate peak from the stressed samples was evaluated from the purity angle and peak threshold data using the PDA detector. The stress parameters, stress conditions, $\%$ degradation in each stress parameter are listed in Table-4. The stress study data indicate that highest degradation was observed in base hydrolysis $(68.1 \%)$, followed by oxidation $(10 \%)$, acid hydrolysis $(3.7 \%)$ and thermal degradations $(2 \%)$. The purity angle was less than the purity threshold in all the stress conditions which indicates that mycophenolate peak is homogeneous in presence of its degradation impurities and the method is stability indicating.

Linearity: Linearity of detector response against the standard concentration was demonstrated from 25 to $150 \%$ of $125 \mu \mathrm{g}$ $\mathrm{mL}^{-1}$ using minimum six calibration levels $(25,50,75,100$, 125 and $150 \%$ ). The linearity solutions were prepared from a standard stock solution by appropriate dilutions and each solution was chromatographed. The area response was recorded and the data was evaluated by using linear regression method. Tables 5 and 6 summarizes the linearity results and regression parameters. The obtained data shows an excellent correlation $\left(\mathrm{R}^{2}>0.9999\right)$ between the peak area and mycophenolate concentration which indicates that the method follows a linear fit model.

\begin{tabular}{cccc}
\multicolumn{4}{c}{ TABLE-5 } \\
& RESULTS OF LINEARITY \\
\hline S. No. & Level $(\%)$ & $\begin{array}{c}\text { Concentration } \\
\left(\mu \mathrm{mL}^{-1}\right)\end{array}$ & $\begin{array}{c}\text { Average area } \\
\text { counts }\left(\mu v^{*} \mathrm{sec}\right)\end{array}$ \\
\hline 1 & 25 & 31.25 & 133036 \\
2 & 50 & 62.5 & 263021 \\
3 & 75 & 93.75 & 399462 \\
4 & 100 & 125.0 & 532632 \\
5 & 125 & 156.25 & 666808 \\
6 & 150 & 195.3141 & 830176 \\
\hline
\end{tabular}

\begin{tabular}{clc}
\multicolumn{3}{c}{ TABLE-6 } \\
& \multicolumn{1}{c}{ SUMMARY OF REGRESSION PARAMETERS } \\
\hline S. No. & \multicolumn{1}{c}{ Parameter } & Obtained values \\
\hline 1 & Correlation coefficient & 0.9999 \\
2 & Slope & 4263.2 \\
3 & Y-Intercept & -987.51 \\
4 & Residual sum of squares & 12754809 \\
\hline
\end{tabular}

Accuracy: The study of accuracy was performed by recovery method using a known amount of active pharmaceutical ingredient (mycophenolate mofetil API) in fixed amount of placebo. Samples were prepared as per the proposed method at three levels i.e., 50, 100 and $150 \%$ of target analyte concentration $\left(125 \mu \mathrm{g} \mathrm{mL}^{-1}\right)$ in triplicate $(\mathrm{n}=3)$. Each preparation was injected in duplicate $(\mathrm{n}=2)$ into the chromatographic system. For each recovery level, \% mean recovery was calculated (Table-7). Mean and \% relative standard deviation of all three recovery levels were calculated and assessed for accuracy of the method. The $\%$ mean recovery was between 98.6 and 100.0 , which is well within the acceptance criteria. The relative standard deviations of all three levels are between 0.2 to $0.6 \%$, which indicates that the method can extract analyte from the sample matrix accurately and precisely.

Method precision and intermediate precision (ruggedness): The repeatability of the method was established by preparing and injecting six samples as per the optimized methodology $\left(125 \mu \mathrm{g} \mathrm{mL}^{-1}\right)$. Intermediate precision was carried out by analyzing six samples on different instrument, different 


\begin{tabular}{|c|c|c|c|c|c|c|}
\hline \multicolumn{7}{|c|}{$\begin{array}{c}\text { TABLE-7 } \\
\text { RESULTS OF ACCURACY }\end{array}$} \\
\hline S. No. & Recovery levels & Amount added (mg) & Amount recovered (mg) & Recovered (\%) & Mean recovery $(\%)$ & $\operatorname{RSD}(\%)$ \\
\hline 1 & $50 \%$ & 19.59 & 19.29 & 98.5 & 98.6 & 0.2 \\
\hline 2 & $50 \%$ & 19.59 & 19.36 & 98.8 & & \\
\hline 3 & $50 \%$ & 19.59 & 19.28 & 98.4 & & \\
\hline 1 & $100 \%$ & 39.06 & 39.38 & 100.6 & 100.0 & 0.6 \\
\hline 2 & $100 \%$ & 39.06 & 38.97 & 99.8 & & \\
\hline 3 & $100 \%$ & 39.06 & 38.87 & 99.5 & & \\
\hline 1 & $150 \%$ & 58.5 & 57.95 & 99.1 & 99.1 & 0.2 \\
\hline 2 & $150 \%$ & 58.5 & 57.92 & 99.0 & & \\
\hline 3 & $150 \%$ & 58.5 & 58.10 & 99.3 & & \\
\hline
\end{tabular}

day and using different column. The system suitability results obtained in method precision and intermediate precision are compared and tabulated in Table-8. The data shows that the system suitability parameters from different day analysis are comparable. A comparison of method precision and intermediate precision results is given in Table-9. The results indicate that the method precision results range from 97.9 to $99.7 \%$ with an RSD of $0.6 \%$ and the intermediate precision results range from 98.7 to $99.3 \%$ with an RSD of $0.24 \%$. The statistics of $\mathrm{n}=12$ results $\left(\mathrm{RSD}_{12}=0.45 \%\right)$ shows that the proposed method is precise.

TABLE-8

\section{COMPARISON OF SYSTEM SUITABILITY PARAMETERS}

\begin{tabular}{lcc}
\hline \multicolumn{1}{c}{ System suitability parameters } & $\begin{array}{c}\text { Method } \\
\text { precision }\end{array}$ & $\begin{array}{c}\text { Intermediate } \\
\text { precision }\end{array}$ \\
\hline Retention time (min) & 1.740 & 1.728 \\
USP tailing & 1.0 & 1.0 \\
USP plate count & 21034 & 22350 \\
RSD (\%) of five standard injections & 0.3 & 0.4 \\
\hline
\end{tabular}

\begin{tabular}{ccc}
\multicolumn{4}{c}{ TABLE-9 } \\
COMPARISON OF METHOD PRECISION AND \\
INTERMEDIATE PRECISION RESULTS \\
\hline \multirow{2}{*}{ Sample No. } & \multicolumn{2}{c}{ Assay (\%) } \\
\cline { 2 - 3 } & Method precision & Intermediate precision \\
\hline 1 & 99.4 & 99.3 \\
2 & 97.9 & 99.0 \\
3 & 99.2 & 99.2 \\
5 & 99.7 & 99.2 \\
6 & 99.1 & 98.8 \\
Mean $(\mathrm{n}=6)$ & 99.1 & 98.7 \\
RSD $(\%)(\mathrm{n}=6)$ & 99.1 & 99.0 \\
\hline Mean $(\mathrm{n}=12)$ & 0.62 & 0.24 \\
RSD $(\%)(\mathrm{n}=12)$ & \multicolumn{3}{c}{99.0} \\
\hline
\end{tabular}

Range: The range of the analytical method is the working analyte (mycophenolate mofetil) concentration between which the method is precise, accurate and linear. From the above validation data, the range of the method falls between 50 to $150 \%$ of analyte concentration $\left(125 \mu \mathrm{g} \mathrm{mL}^{-1}\right)$ in the sample for which it has been demonstrated to have a suitable level of precision, accuracy and linearity.

Limit of detection and limit of quantification: The limit of detection was defined as the lowest concentration of the analyte that can be detected with $\mathrm{S} / \mathrm{N}$ ratio $3: 1$. The limit of quantitation was defined as the lowest concentration of the analyte that can be quantified accurately and precisely with $\mathrm{S} / \mathrm{N}$ ratio $10: 1$. The limit of detection (LOD) and limit of quantification (LOQ) were estimated by using slope and standard deviation method. The obtained LOD and LOQ concentrations were further verified by injecting mycophenolate standard at these concentrations (Table10). The obtained $\mathrm{S} / \mathrm{N}$ ratio met the criteria for LOD and LOQ as per the $\mathrm{ICH}$ guidelines (Q2R).

\begin{tabular}{ccc}
\multicolumn{3}{c}{ TABLE-10 } \\
& RESULTS OF LOD AND LOQ \\
\hline Parameter & $\mu \mathrm{g} \mathrm{m}^{-1}$ & S/N Ratio \\
\hline LOD & 1.2566 & 5 \\
LOQ & 4.1887 & 14 \\
\hline
\end{tabular}

Solution stability: A study to establish stability of analytical solution (standard and sample) was conducted at 2 to $8{ }^{\circ} \mathrm{C}$. Standard and sample solutions were prepared as per the proposed method and an aliquot was kept in refrigerator for $24 \mathrm{~h}$. After $24 \mathrm{~h}$, the two solutions were chromatographed and the area response was compared with that of a freshly prepared standard. For assessing the sample solution stability, difference between values of initial and $24 \mathrm{~h}$ assays were calculated. The data obtained from the study are presented in Table- 11 .

\begin{tabular}{cccc}
\multicolumn{5}{c}{ TABLE-11 } \\
STABILITY OF ANALYTICAL SOLUTIONS \\
\hline \multirow{4}{*}{ Sample No. } & $\begin{array}{c}\text { Snitial result } \\
(\% \mathrm{w} / \mathrm{w})\end{array}$ & $\begin{array}{c}\text { Results after } \\
24 \mathrm{~h}(\% \mathrm{w} / \mathrm{w})\end{array}$ & $\begin{array}{c}\text { Absolute } \\
\text { difference }\end{array}$ \\
\cline { 2 - 4 } & 98.7 & 99.1 & 0.4 \\
\hline Sample-1 & 98.9 & 99.0 & 0.1 \\
Sample-2 & Standard solution stability \\
\hline \multicolumn{4}{c}{ Similarity } \\
Standard peak name & - & factor & - \\
Mycophenolate mofetil & - & 1.00 \\
\hline
\end{tabular}

Robustness: Robustness study was performed on the chromatographic parameters which are susceptible to change during the preparation of solution, handling and operation of the instrument. The parameters studied are mobile phase flow rate, column oven temperature and mobile phase $\mathrm{pH}$. The mobile phase flow rate was studied at $\pm 10 \%$ from the optimized flow rate. The column oven temperature on was studied at $\pm 5^{\circ} \mathrm{C}$. The variation in mobile $\mathrm{pH}$ was studied at \pm 0.2 units. The response factors observed during the robustness study are retention time (RT), USP resolution, USP Plate counts and relative standard deviation. The data shows that the change in mobile phase flow rate and mobile phase $\mathrm{pH}$ has considerable 


\begin{tabular}{|c|c|c|c|c|c|c|c|}
\hline \multicolumn{8}{|c|}{$\begin{array}{c}\text { TABLE-12 } \\
\text { RESULTS OF ROBUSTNESS/RUGGEDNESS EXPERIMENT }\end{array}$} \\
\hline S. No. & Robustness parameter & $\begin{array}{c}\text { Actual } \\
\text { condition }\end{array}$ & $\begin{array}{c}\text { Altered } \\
\text { condition }\end{array}$ & $\begin{array}{l}\text { Retention time of } \\
\text { mycophenolate (min) }\end{array}$ & $\begin{array}{c}\text { USP } \\
\text { resolution }\end{array}$ & $\begin{array}{c}\text { USP plate } \\
\text { count }\end{array}$ & $\operatorname{RSD}(\%)$ \\
\hline 1 & Control & - & - & 1.790 & 2.4 & 23710 & 0.20 \\
\hline \multirow{2}{*}{2} & \multirow{2}{*}{ Flow $\left(\mathrm{mL} \min ^{-1}\right)$} & \multirow{2}{*}{0.3} & 0.27 & 1.901 & 2.5 & 21084 & 0.32 \\
\hline & & & 0.33 & 1.545 & 2.1 & 22133 & 0.30 \\
\hline \multirow[b]{2}{*}{3} & \multirow{2}{*}{ Column oven temperature $\left({ }^{\circ} \mathrm{C}\right)$} & \multirow{2}{*}{45} & 40 & 1.789 & 1.7 & 19039 & 0.43 \\
\hline & & & 50 & 1.677 & 2.5 & 20334 & 0.44 \\
\hline \multirow{2}{*}{4} & \multirow{2}{*}{ Mobile phase $\mathrm{pH}$} & \multirow{2}{*}{4.5} & 4.3 & 1.821 & 2.2 & 19304 & 0.40 \\
\hline & & & 4.7 & 1.656 & 2.3 & 21203 & 0.20 \\
\hline
\end{tabular}

effect on the retention behaviour of mycophenolate mofetil and USP resolution between USP related compound B and mycophenolate mofetil peak. Rest of the other parameters do not have much impact on the system suitability parameters. Table-12 shows the compilation of the robustness parameters and response observed. A graphical representation of retention behaviour and USP resolution versus robustness parameters is shown in Fig. 14.

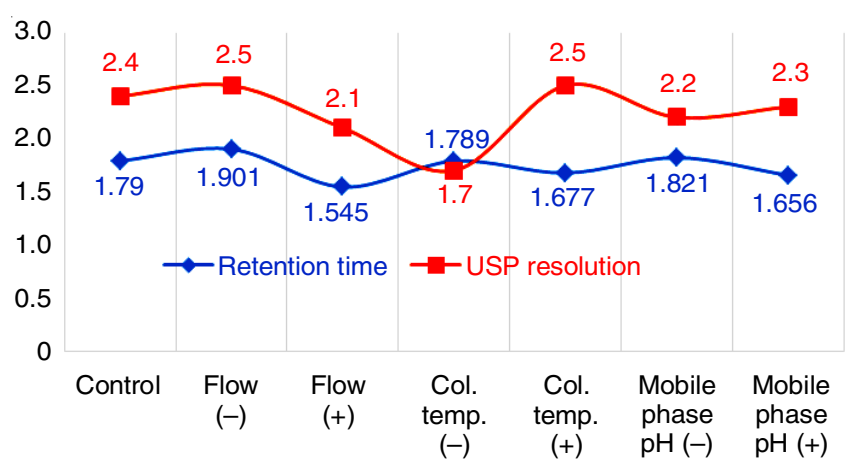

Fig. 14. Retention time and USP resolution vs. robustness parameters

\section{Conclusion}

A rapid, simple, sensitive, accurate and reliable RP-UPLC method was developed and validated for the determination of mycophenolate in injection formulations as per the ICH guidelines. In this method mycophenolate mofetil was separated from its seven impurities in 9 min of chromatographic run time and quantified with high degree of accuracy and precision. The retention time for mycophenolate was found to be $1.7 \pm$ $0.2 \mathrm{~min}$. Another advantage with this method is, it can be employed for mass determinations on LC-MS system, as its optimized buffer and mobile phase are compatible to mass spectrometry. The stability indicating power of the method was established through stress studies. All the degradation products formed during stress studies were well separated from the analyte peak which is evident from the peak purity data. The method discusses the nature of the molecule under stress conditions where it was shown that the compound is sensitive towards base hydrolysis $(68.1 \%)$, followed by oxidation (10\%), acid hydrolysis $(3.7 \%)$ and thermal degradations (2\%). The validation data meets the acceptance criteria for the validation parameters as per the current ICH (Q2R) and AOAC guidelines.

\section{REFERENCES}

1. K.P. Platz, H.W. Sollinger, D.A. Hullett, D.E. Eckhoff, E.M. Eugui and A.C. Allison, Transplantation, 51, 27 (1991); https://doi.org/10.1097/00007890-199101000-00003.
2. E.M. Eugui, S.J. Almquist, C.D. Muller and A.C. Allison, Scand. J. Immunol., 33, 161 (1991); https://doi.org/10.1111/j.1365-3083.1991.tb03746.x.

3. T.R. Srinivas, J.D. Schold, G. Guerra, A. Eagan, C.M. Bucci and H.U. MeierKriesche, Am. J. Transplant., 7, 586 (2007); https://doi.org/10.1111/j.1600-6143.2006.01658.x.

4. S.M. Flechner, L. Zhou, I. Derweesh, B. Mastroianni, K. Savas, D. Goldfarb, C.S. Modlin, V. Krishnamurthi and A. Novick, Transplantation, 76, 1729 (2003); https://doi.org/10.1097/01.TP.0000093502.26208.42.

5. Drug bank, Mycophenolate Mofetil; https://www.drugbank.ca/drugs/DB00688.

6. National Library of Medicine, USA, extracted from ChemIDplus, UNII: 9242ECW6R0;

https://chem.nlm.nih.gov/chemidplus/rn/128794-94-5.

7. Mycophenolate Mofetil Monograph; United States Pharmacopoeia; USP40 NF35; 2017; p. 5247 (2017).

8. P.W. Brian and H.G. Hemming, Microbiology, 1, 158 (1947).

9. P.W. Clutterbuck, A.E. Oxford, H. Raistrick and G. Smith, Biochem. J., 26, 1441 (1932); https://doi.org/10.1042/bj0261441.

10. J.H. Birkinshaw and M.S. Samant, Biochem. J., 74, 369 (1960); https://doi.org/10.1042/bj0740369.

11. W. Harrison, H.M. Shearer and J. Trotter, J. Chem. Soc., Perkin Trans. 2, 1542 (1972); https://doi.org/10.1039/p29720001542.

12. Mycophenolate Mofetil Injection, USP40-NF35, The United States Pharmacopoeia Convention, Inc., Rockville, MD, p. 5250 (2017).

13. Mycophenolate Mofetil Tablet, USP40-NF35, The United States Pharmacopoeia Convention, Inc., Rockville, MD, p. 5253 (2017).

14. Mycophenolate Mofetil Capsule, USP40-NF35, The United States Pharmacopoeia Convention, Inc., Rockville, MD, p. 5248 (2017).

15. Mycophenolate Mofetil for Oral Suspension, USP40-NF35, The United States Pharmacopoeia Convention, Inc., Rockville, MD, p. 5253 (2017).

16. Mycophenolate Mofetil Monograph; European Pharmacopoeia, European Directorate for the Quality of Medicine \& Health Care of the Council of Europe (EDQM), edn 9, vol. 3, pp. 3104-3105 (2016).

17. Mycophenolate Mofetil; Mycophenolate Capsules Monograph, Indian Pharmacopoeia, pp. 2268-2270 (2014).

18. I. Tsina, M. Kaloostian, R. Lee, T. Tarnowski and B. Wong, J. Chromatogr. B Biomed. Sci. Appl., 681, 347 (1996); https://doi.org/10.1016/0378-4347(96)00038-2.

19. A.L. Rao, P.V. Srinivas and J.V. Rao, Asian J. Pharm. Res. Health Care, 2, 266 (2010).

20. P.R. Abhilash, K.V. Kumar and V.S. Kumar, Br. J. Pharm. Res., 3, 363 (2013); https://doi.org/10.9734/BJPR/2013/2286.

21. T.V. Reddy, G. Ramu and C. Rambabu, Anal. Chem.: An Indian J., 12, 156 (2013).

22. V.P. Choudhari and A.P. Nikalje, Adv. Chem., Article ID 719385 (2014); https://doi.org/10.1155/2014/719385.

23. M. Bolon, L. Jeanpierre, M. El Barkil, K. Chelbi, M. Sauviat and R. Boulieu, J. Pharm. Biomed. Anal., 36, 649 (2004); https://doi.org/10.1016/j.jpba.2004.07.034.

24. M. Shipkova, P.D. Niedmann, V.W. Armstrong, E. Schütz, E. Wieland, L.M. Shaw and M. Oellerich, Clin. Chem., 44, 1481 (1998).

25. D. Teshima, K. Otsubo, N. Kitagawa, S. Yoshimura, Y. Itoh and R. Oishi, J. Clin. Pharm. Ther, 28, 17 (2003); https://doi.org/10.1046/j.1365-2710.2003.00450.x. 
26. C.G. Patel, A.E. Mendonza, F. Akhlaghi, O. Majid, A.K. Trull, T. Lee and D.W. Holt, J. Chromatogr. B Analyt. Technol. Biomed. Life Sci., 813, 287 (2004);

https://doi.org/10.1016/j.jchromb.2004.10.004.

27. D.G. Watson, F.G. Araya, P.J. Galloway and T.J. Beattie, J. Pharm. Biomed. Anal., 35, 87 (2004); https://doi.org/10.1016/j.jpba.2003.12.011.

28. M.A. Barzoki, M. Rouini, K. Gholami, M. Lessan-Pezeshki and S. Rezaee, Daru, 13, 120 (2005).

29. G. Khoschsorur and W. Erwa, J. Chromatogr. B Analyt. Technol. Biomed. Life Sci., 799, 355 (2004); https://doi.org/10.1016/j.jchromb.2003.10.074.

30. D.V. McCalley and R.G. Brereton, J. Chromatogr. A, 828, 407 (1998); https://doi.org/10.1016/S0021-9673(98)00590-1.

31. W.R. Melander, J. Stovekeen and C. Horvàth, J. Chromatogr. A, 185, 111 (1979);

https://doi.org/10.1016/S0021-9673(00)85601-0.
32. The United States Pharmacopoeia 40 National Formulary 35, Description and Solubility (5.30); General Notices; The United States Pharmacopoeia Convention, Inc., Rockville, MD (2017).

33. J.J. Kirkland, M.A. Van Straten and H.A. Claessens, J. Chromatogr. A, 691, 3 (1995); https://doi.org/10.1016/0021-9673(94)00631-I.

34. L.R. Snyder, J.J. Kirkland and J.L. Glajch, Practical HPLC Method Development, John Wiley \& Sons (2012).

35. R.M. Kennedy, Methods Enzymol., 182, 339 (1990); https://doi.org/10.1016/0076-6879(90)82029-2.

36. HSS C18; Waters catalogue, Waters Acquity UPLC HSS Columns, Retrieved from.

37. https://www.waters.com/webassets/cms/support/docs/715001429.pdf.

38. H. Colin and G. Guiochon, J. Chromatogr. A, 141, 289 (1977); https://doi.org/10.1016/S0021-9673(00)93537-4.

39. H. Engelhardt and G. Ahr, Chromatographia, 14, 227 (1981); https://doi.org/10.1007/BF02260156. 